\title{
Hansel Staining Method
}

National Cancer Institute

\section{Source}

National Cancer Institute. Hansel Staining Method. NCI Thesaurus. Code C111205.

A microscopy staining method that utilizes Hansel reagent to differentiate eosinophils and neutrophils in a specimen. $(\mathrm{NCl})$ 